Information Management and Business Review

Vol. 3, No. 2, pp. 127-132, Aug 2011 (ISSN 2220-3796)

\title{
Influential Role of Culture on Leadership Effectiveness and Organizational Performance
}

\author{
*Syed Kamran Ali Shah, Jam Javed Iqbal, Adeel Razaq, Muhammad Yameen, Suleman Sabir, Muhammad Asif Khan \\ Iqra University Islamabad, Pakistan \\ *kamran_bukhari@hotmail.com
}

\begin{abstract}
The purpose of this research paper is to examine the influential role of culture on leadership effectiveness and organizational performance in Pakistan. Culture is discussed with its two dimensions, national and organizational culture. In this competitive and globalized arena, culture plays a significane role in the organizational performance and leadership effectiveness. It was also found that supportive leadership style is frequent in most of the orgnaizations in Pakistan. Participative leadership style has also a positive impact on organizational performane and leadership effectiveness but to some extent, but instrumental leadership style has a negative impact. This research paper is exploratory in nature which explains the importance of leadership styles and its impact on decision making which influence the overall performance of the organization. Our study is limited regarding the national culture and organizational culture as a mediating role. Practically there is some diversity among cultures of the Pakistani organizations which leades to the diversity in the leadership behavior.
\end{abstract}

Keywords: Organizational culture, National culture, Leadership effectiveness, Organizational performance, Leadership styles

\section{Introduction}

Researchers have been very eager to unfold the relationship between personalities and human behavior of those people who have different background relevant to their attitudes, values, culture, norm, traditions on the basis that determines their actions and behavior (Savery, 1994). Because in this world, all the people have different attributes of personalities. Some of them have strong personalities through which they can guide the people to act and behave depending on the behavior of the organization. Personality refers to the uniqueness of the, anyone that account for reliable patterns of accepted wisdom, sentiment, and behaving (Pervin et al, 2005). It is very hard to describe the word Personality. Surprisingly there are 17953 words to describe others personalities. So, researchers have described five dimensions to define personality.

Leadership is not an inherited thing but comes from the personality attributes which are the essential elements of the effective leadership (Hogan et al, 1994). Leadership can be a strong weapon for influencing the people or group of people towards achieving organizational specific goals. By birth, no body can be a leader. So, the leaders can urge the people in achieving organizational goals. Leadership is the combination of different characteristics or attributes such as dominance, ambitiousness, risk taking, independence, assertiveness, self sufficiency, self reliance etc. and the people having these attributes called as "leaders". So, an affective leader is a person who can stimulate the interest of the people or a group of people to accomplish the organizational tasks. An individual can not complete different tasks of the organization but it is the leader who can combine different people into a team and leads towards one destination i.e. the goals of organization (Ismael \& Nor'y, 2010).

In this competitive arena, leaders think that internal changes are one of the many key elements to deal effectively with external changes in environment. This change is the key component of the leadership effectiveness. So, the leader can lead the organization into a right direction. Daft (2005) mention that strong and committed leadership is very crucial to successful change. Moreover all the managers cannot be leaders in an organization where leader's dominant role is to bring about the change through communication and motivation. It is possible that in an organization one manager could succeed to bring change but other fail. Same is the case that all the managers can not be effective. Personality of the manager is the only way for effectiveness of leadership. A lot of motives can be helpful for the effective leadership such as leadership styles, age, experience, gender, and educational background (Ogbonna \& Harris, 2000). So every manager has 
his own personality trait and leadership style. There are some dimensions of personality traits like Agreeable, extroversion, autocratic, or democratic. And a manager may fall any one of these dimensions depending upon their personality trait.

Alvesson (1990) explained culture as something which citizens encompass, believe and act as an integral part of their civilization and by Hofstede (1991) as the cultivation of the mentality. Culture plays a dominant part in the society. Culture is important for shaping the people and organizational perceptions, attitude, behavior, state of mind, norms and values. An organizational values and norms are not twisted through dialogues rather we can make it through procedures and team wisdom. Leadership has a great influence on the followers for the accomplishment of tasks and also helpful for the organizations to makes it more consistent and rational. An organizational culture has a considerable collision on its talent to implement its plan and to attain organizational objectives and goals. If a culture and its employment atmosphere are refined purposely, it expands significantly the organizational capability to accomplish its objectives. So, organizational culture is helpful in this scenario to dig out the problems and to find out its solutions depending upon their feelings and learning to set the prospects, morality, performance, examples and customs that extend a high rank of success (Marcoulides \& Heck, 1993, Schein, 1992).

It has been proved that organizational culture is very crucial for the efficiency and effectiveness of the businesses due to diversed behavior of the organizations, environments and the war of technology. There is a dominant relationship between national culture and organizational culture with leadership effectiveness (Borman \& Motowidlo, 1993; Organ, 1988; Van Scotter \& Motowidlo, 1996). Cross-cultural barriers are the major hindrance for the capitalization of ability and expertise for the diversity management to boost up the organization. So, the leaders are the model role to revamp the organizational culture to enhance the productivity and performance of the organization (Lok \& Crawford, 1999).

So, it is tried in this paper to explain that the leaders should avoid the varying bahavior or style as these are harmful for the organizational performance (Liliana, Emilio, \& Juan, 2006). The leaders have the strong influence on the organizational culture having different standards and ethics in relation with the national culture whish also has the customs and values in order to shrink the repulsive affect of cultural diversity. Basically it is the leader's responsibility to exchange the existing orientations and goals with new ones which are very helpful to create a strong organizational as well as national culture for the enhancement of the performance (Schein, 1992). In start of this paper it is tried to differentiate between the organizational culture and the national culture. Then what are the views of the former authors regarding influence of organizational culture and national culture on the organizational performance.

\section{Literature Review}

According to Liliana, Emilio and Juan (2006), the supportive leadership style is mainly concerned with establishing good relationship, friendly environment and well being of the employees to fulfill their needs and wants. A study of the many organizations shows that supportive leadership style is more prominent than participative and instrumental leadership style. The participative leadership has positive relationship with leadership effectiveness as compared to supportive leadership style and instrumental leadership style has no positive relationship in small organizations. Therefore, the most frequent style of leadership adopted by the small organizations is the supportive leadership style. The supportive and participative leadership styles have direct relationship with leadership effectiveness of small organizations.

Culture is a very complex topic, therefore in every era; culture has defined in different perspective throughout the history. The concept of the organizational culture mainly focused after the discovery of the relationship between culture and performance. In present era, the organization world has standard meaning and definition in the management dictionary because of its importance and practices. It is the most difficult to elaborate the organizational culture in universal form because of cultural differences. Schein, a well known organizational theorist has developed organizational culture model in which culture referred to the combined knowledge shared by a group of associates within the society. This model moved the confusion that, there are three different stages which shape the organizational culture; artifact, bottom line artifact and deepest level. 
The visible and tangible product referred to surface of culture (artifact). The next stage of culture is ethics and norms (bottom line artifact) which are referred as associates ethics as actual and accurate. This stage leads towards the ethical supervision of the group of members. The third level of culture, unconscious taking for a granted believes and feeling of the members. The model of Schien shows that how culture works, driven by values and norms of organization and organizational unity. Therefore, author defined the culture as "the collective strength of norms and values (Schein, 1992).

Organizational culture forms the way that how people react, reply and manipulate how things can be accomplished. It covers the organizational behavioral norms, objects, and central considerations. Culture can also be articulated through the organizational heroes, myths, stories, legends, rites, rituals, and jargons. Organizational culture is the key factor for the achievement of organizational tasks and plans, to improve the organizational success and the alliance of change. A corporate culture can also be a weapon to improve performance or it can be harmless to create obstructions that avert the achievement of targets. However it can be streamline by proper guidance by creating a sense of responsibility and propose to achieve goals between the members. A well known Dutch behavioral Scientist, Geert Hofstede explains culture "as the collective programming of the mind which distinguishes the members of one group form another". Organizational culture defines a future course of action. It is the hub for team construction. It also provides the common purpose to the members of organization. So, organizational culture is the key consideration for the critical basis which helps that how work get done and how infrastructure could be operated. Seven dimensions are most important for organizational performance and leadership effectiveness which are novelty and hazardness, result oriented, people orientation, constancy, attention to detail, assertiveness and team orientation. So, matching organizational culture with strategy is a strong way for the attainment of competitive advantage for leadership effectiveness and organizational performance (Kefala, 2010).

National culture and cultural diversity mainly based on five pillars as defined by the Dutch behavioral scientist, Hofstede (1991) which are power distance, individualism, masculinity, uncertainty avoidance and long term orientation. Each pillar of the culture supports us to forecast and describe the norms, values, attitude, behavior, needs and wants of people regarding specific configuration. One leadership style that fit in specific region and gives high performance would not give same performance in the other region because of cultural differences. The culture configuration of Hofstede shows that effective leadership reacted differently to across the cultural dimensions. And having same culture configuration lead the employee motivation which give high performance. This study shows that different leadership styles for different culture are most suitable. Therefore each leader of specific organization should have good understanding of national culture differences that will take toward the high performance (Popper \& Mayseless, 2007).

Leadership and Organizational Performance Relationship: During the past two or three decades, it was the burning question between the academics and researchers of leadership that there is a strong impact of leadership styles on organizational performance (Klagge, 1997). The most dominant reason for this impact is that the organizational performance can be affected by the leadership. So, it is clearly stated that leadership has a strong link between the performance of the people and organizational effectiveness at a level of organization. There are many causes which show that there should be a strong relationship between the organizational performance and leadership depending upon the cultural variables. Researchers and scholars strongly point out that the behavior of effective leadership can assist in the improvement of organizational performance (Fenwick \& Gayle, 2008).

Effective leadership is the major source for the development of the management and to get the competitive advantage to improve the organizational performance. 


\section{Theoretical Framework}

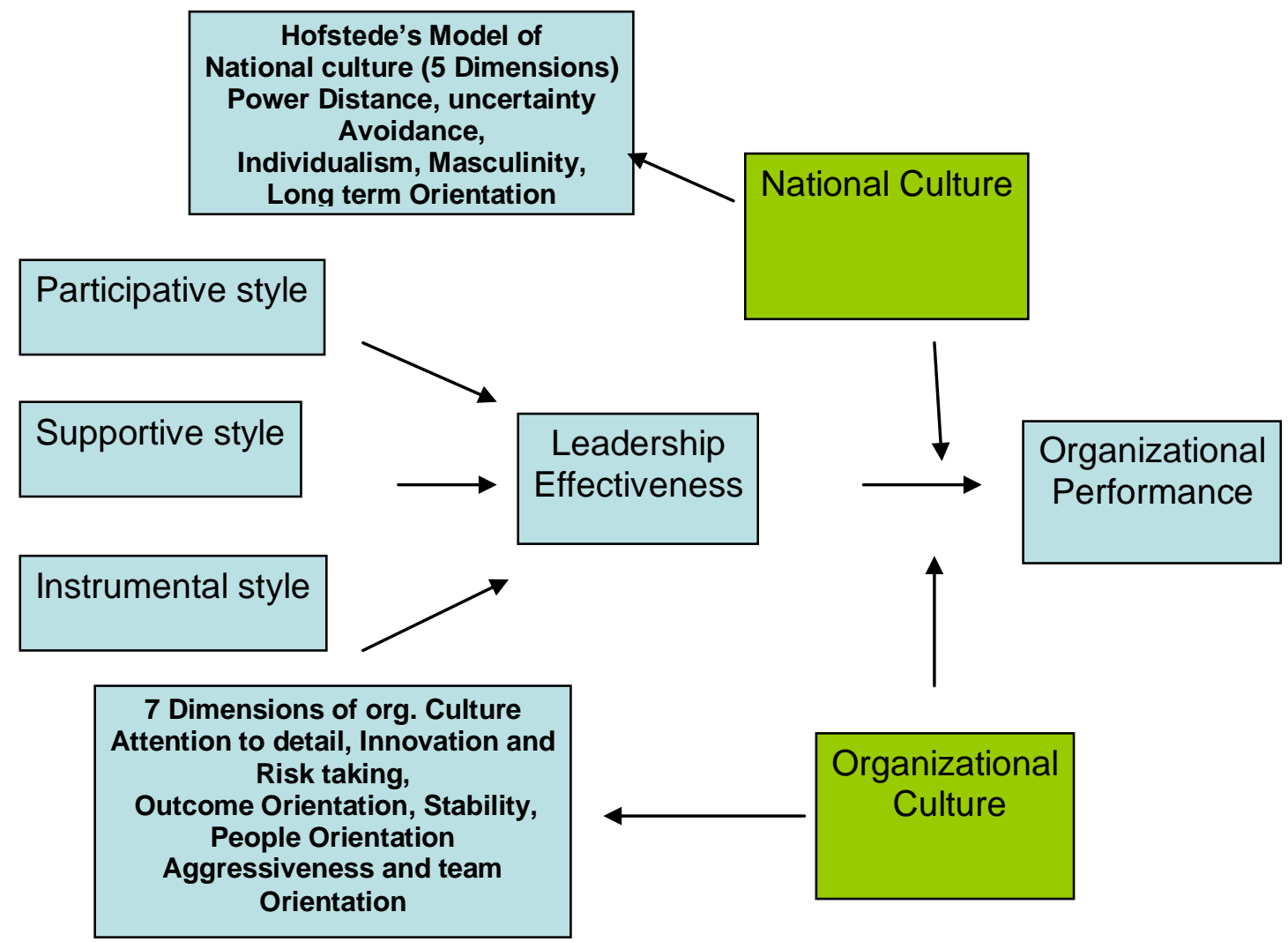

\section{Hypotheses}

H1 Has Leadership effectiveness strong relationship with Organizational Performance?

H2 Influence of National Culture between the leadership effectiveness and organizational performance.

H3 Influence of organizational culture between the leadership effectiveness and organizational performance

\section{Discussion}

According to Schein (1992), organizational culture is the most different issue in the world due to cultural differences among the countries as well as for organizations. Schein (1992), model of organizational culture showed its different levels including norms and values which affect the organizational performance in different angles. The positive culture of the organization affects the organizational performance in positive directions and takes it to the prosperity. The organizational culture mainly concentrated on the leadership/management's commitment and involvement in the organizational tasks (Lok \& Crawford, 1999). The commitment of the top level management towards the achievements of the goals can never be failed. Therefore the leadership effectiveness is affected by the culture and has the positive impact on the organizational performance. We also concluded from the secondary data collection that strong culture has direct relationship with leadership effectiveness and also observed in the literature review that the apex level of organizational performance lead by the leadership effectiveness and efficiency (Rajiv et al, 2001). Organizational culture teaches the people about the achievement of the goals within the organization. So an organizational culture is the stick which guides the employees how to manipulate and respond with respect 
to their capabilities (Nancy \& Eleanna, 2008). So, there must be a match between organizational culture, leadership effectiveness and organizational performance (Dag, 2006).

In 1980, Hofstede introduced 5 dimensions of national culture and each pillar of the culture described routines, norms and attitudes of people. These dimensions of culture lead the employees' motivation towards high performance of the organization and dimensions actions are not the same all over the world. It affects the leadership effectiveness in different regions differently. There is no doubt that organizational culture comes form the national culture and if there is mismatch between organizational culture and national culture then these organizations can never survive in the society. Therefore national culture affects the organizational culture, and plays a key role in leadership effectiveness. So, Hofstede model of national culture is the base for the development of the personality of the leaders and effectiveness of the leadership for the organizational performance. We examined from the literature review and secondary data that national culture has strong and positive relationship with organizational performance.

All leadership styles have strong impact on the organizational performance with different levels of effectiveness (Mannion, 2009). There is a strong relationship between the leadership styles and organizational performance. In the literature review, we observed that different authors argue that effective leadership supports the organization in improving performance on continuous basis. We identified three styles of leadership among the different styles; participative, supportive and instrumental styles. Each style has its own importance but the supportive style has much positive influence on the leadership which gives the optimum level of performance to the organization (Houghton \& DiLiello, 2010). We found through literature review and secondary data collection that supportive leadership effectiveness has direct relationship with organizational performance (Casimir, 2010).

\section{Conclusion}

We studied different aspects of national culture through Hofstede model and different dimensions of organizational culture through different resources. We also examined a mediating role of national culture and organizational culture in leadership relationship with organizational performance. The leadership effectiveness regarding these styles is different at different levels of the organization. We concluded that supportive leadership style is the best for leadership effectiveness. The mediating variables, national culture and organizational culture affect the leadership styles and its impact on organizational performance. The organizational performance can be achieved through leadership effectiveness. We concluded from our study that leadership effectiveness has positive relationship with organizational performance. The organizational performance can be increased with the increasing leadership effectiveness.

Recommendations: While it is anticipated that this research will open new horizon for the followers to expand it into a new direction, but without an added exploration, the relationship between culture, leadership and performance will remain perplexing for experts and researchers.

Our study is limited regarding the national culture and organizational culture as a mediating role. The researchers and the followers can use the other different models of national culture except Hofstede model and also verify the strong and weak organizational culture impact on leadership effectiveness as well as the organizational performance. The Researchers may increase the leadership styles or used different styles and their relation with leadership effectiveness.

\section{References}

Alvesson, M. (1990). On the Popularity of Organizational Culture. Acta Sociologica, 1, 31-49.

Borman, W. C. \& Motowidlo, S. J. (1993). Expanding the criterion domain to include elements of contextual performance. In N. Schmitt \& W. Borman (Eds.). Personal Selection in organizations, 71-98. New York: Jossey-Bass.

Casimir, G. (2010). Combinative aspects of leadership style and the interaction between leadership behaviors. Leadership \& Organization Development Journal, 31 (6), 501-517. 
Daft, L. (2005). The Leadership Experience, $3^{\text {rd }}$ Edition.

Dag, A. S. (2006) Leadership Practices and Organizational Performance- a Norwegian study, EDAMBA Journal. Fenwick, F. J. \& Gayle, C. A. (2008). Missing Links in Understanding the Relationship between Leadership and Organizational Performance. International Business \& Economic Research Journal, 7(5), 67-78.

Hogan, R., Curphy, J. G. \& Hogan, J. (1994). What we know about leadership: Effectiveness and personality. American Psychological Association, 49(6), 493-504.

Hofstede, G. (1991). Culture and organization: Software of the Mind. London: McGraw-Hill.

Houghton, J. D. \& DiLiello, T. C. (2010). Leadership development: the key to unlocking individual creativity in organizations. Leadership \& Organization Development Journal, 31(3), 230-245.

Ismael, Y. \& Nor'y B. (2010). The Impact of Personality Traits and Leadership Styles on Leadership Effectiveness of Malaysian Managers. Academic leadership, The Online journal, 9(2).

Kefela, T. G. (2010). Understanding Organizational Culture and Leadership-Enhance Efficiency and Productivity. PM World Today-The Featured Journal, 12(1), 1-14.

Klagge, J. (1997). Leadership development needs of today's organizational managers. Leadership \& Organization Development Journal, 18(7), 355-362.

Liliana P. R., Emilio, R. \& Juan, R. P. (2006). Leadership Styles and effectiveness: A study of Small Firms in Chile. Interciencia, 31(7), 500-504.

Lok, P. \& Crawford, J. (1999). The relationship between commitment and organizational culture, subculture, leadership style and job satisfaction in organizational change and development. Leadership \& Organization Development Journal, 20(7), 365-373.

Mannion, K. (2009). Leadership for success. Leadership \& Organization Development Journal, 30 (7), 639-648.

Marcoulides, G. \& Heck, R. H. (1993). Organizational Culture and Performance: Proposing and Testing Model. Organizational Science, 4(2), 209-223.

Nancy, P. \& Galanaki, E. (2008). Leadership's impact on employee engagement; Differences among entrepreneurs and professional CEOs. Leadership \& Organizational Development Journal, 30(4), 365385.

Ogbonna, E. \& Harris, C. L. (2000). Leadership Style, organizational culture and performance: Empirical evidence from UK companies. Int. J. of Human Resource Management, 11(4), 766-788.

Organ, D. W. (1988). Organizational Citizenship behavior: The good soldier syndrome. Lexington, MA: Lexington Books.

Pervin, L. A., Cervone, D. \& John, O. P. (2005). Personality: Theory and Research, USA. John Wiley \& Sons.

Popper, M. \& Mayseless, O. (2007). The building blocks of leader development; A psychological conceptual framework. Leadership \& Organization Development Journal, 28 (7), 664-684.

Rajiv, M., Alan, J. \& Rolph, E. (2001). Leadership Style, Motivation and Performance in International Marketing channels; An Empirical Investigation of the USA, Finland and Poland. European Journal of Marketing, $37(1 / 2), 50-85$.

Savery, K. L. (1994). The Influence of the Perceived Styles of Leadership of a Group of Workers on their Attitudes to Work. Leadership \& Organization Development Journal, 15(4), 12-18.

Schein, E. H. (1992). Organizational Culture and Leadership (2nd Ed.). San Francisco: Jossey-Bass.

Van Scotter, J. \& Motowidlo, S. (1996). Interpersonal facilitation and job dedication as separate facets of contextual performance. Journal of Applied Psychology, 81, 525-531. 